\title{
Risk factors for community-acquired pneumonia in adults: a population-based case-control study
}

\author{
J. Almirall*, I. Bolíbar ${ }^{+}$, X. Balanzó*, C.A. González ${ }^{+}$
}

\begin{abstract}
Risk factors for community-acquired pneumonia in adults: a population-based casecontrol study. J. Almirall, I. Bolíbar, X. Balanzó, C.A. González. (C)ERS Journals Ltd 1999. ABSTRACT: Although community-acquired pneumonia (CAP) remains a major cause of hospitalization and death, few studies on risk factors have been performed. $A$ population-based case-control study of risk factors for CAP was carried out in a mixed residential-industrial urban area of 74,610 adult inhabitants in the Maresme (Barcelona, Spain) between 1993 and 1995.

All patients living in the area and clinically suspected of having CAP at primary care facilities and hospitals were registered. In total, 205 patients with symptoms, signs and radiographic infiltrate compatible with acute CAP participated in the study. They were matched by municipality, sex and age with 475 controls randomly selected from the municipal census. Risk factors relating the subject's characteristics and habits, housing conditions, medical history and treatments were investigated by means of a questionnaire.

In the univariate analysis, an increased risk of CAP was associated with low body mass index, smoking, respiratory infection, previous pneumonia, chronic lung disease, lung tuberculosis, asthma, treated diabetes, chronic liver disease, and treatments with aminophiline, aerosols and plastic pear-spacers. In multivariate models, the only statistically significant risk factors were current smoking of $>20$ cigarettes day $^{-1}$ (odds ratio $(O R)=2.77 ; 95 \%$ confidence interval $(C I)$ 1.14-6.70 compared with never-smokers), previous respiratory infection $(\mathrm{OR}=2.73 ; 95 \%$ CI $1.75-4.26)$, and chronic bronchitis (OR=2.22; 95\% CI 1.13-4.37). Benzodiazepines were found to be protective in univariate and multivariate analysis $(\mathrm{OR}=0.46 ; 95 \% \mathrm{CI} 0.23-0.94)$.

This population-based study provides new and better established evidence on the factors associated with the occurrence of pneumonia in the adult community.

Eur Respir J 1999; 13: 349-355.
\end{abstract}

\begin{abstract}
*Critical Care Unit, Hospitals of the Consorci Sanitari de Mataró, Mataró, Barcelona, Spain. 'Institute of Epidemiological and Clinical Research (IREC), Mataró, Barcelona, Spain.
\end{abstract}

Correspondence: J. Almirall

Critical Care Unit

Hospitals of the Consorci Sanitari de

Mataró

Lepant, 13

E-08301 Mataró, Barcelona

Spain

Fax: 3497582930

Keywords: Pneumonia

population

risk factors

Received: April 161998

Accepted after revision October 91998

This study was funded by the Health Research Fund of the Spanish Ministry of Health (expedient 94/0834).
Although community-acquired pneumonia (CAP) remains a major cause of hospitalization and a common cause of death in developed countries, few population-based studies on its incidence and risk factors have been published. In the USA the incidence of CAP has been estimated as 15 episodes for every 1,000 persons per year [1]. Approximately $15 \%$ of pneumonia cases require hospitalization and the mortality rate reaches 24.1 per 100,000 inhabitants, in fifth place after cardiovascular, neoplastic, cerebrovascular and chronic bronchitic (CB) diseases $[2$, 3]. The incidence of CAP is lower in Europe: 5 per 1,000 in people aged 15-79 yrs in England [4], 9 per 1,000 inhabitants $>14$ yrs in Finland [5] and 2.6 per 1,000 persons $>13$ yrs in Spain [6]. Hospitalization rates in these studies were 42,13 and $50 \%$, respectively. The incidence of CAP $[5,7]$ and the length of hospital stay [8] are higher in the elderly than in young adults; hence, the current demographic ageing will lead to worsening of the problem.

Respiratory host defences, through mechanical, humoral and cellular mechanisms, are usually effective against constant exposure to pathogenic agents from the environment and the naso-oropharynx [9]. Failure of these mechanisms may lead to lung infection. Pneumonia is the result of several factors that favour the entrance, establishment and multiplication of pathogenic organisms, as well as factors that decrease the host's respiratory defence mechanisms [10]. Suggested predisposing factors have been lifestyle factors (e.g. chronic and acute alcoholism, smoking and malnutrition), environmental and occupational factors (air pollutants), chronic and debilitating diseases (e.g. diabetes, neoplasms or chronic obstructive pulmonary disease), immunodeficiencies and medical interventions (e.g. immunosuppressive therapies, splenectomy and inappropriate antibiotic treatment) [10].

A population-based case-control study was carried out to assess the risk factors associated with the development of CAP in adult patients.

\section{Materials and methods}

\section{Study subjects}

The study was conducted in a mixed residential-industrial urban area of 74,610 inhabitants of $>14$ yrs of age in the Maresme county (Barcelona, Spain), which is situated on the Mediterranean coast. This area was selected because all of the physicians who were first contacted by the 
patient with symptoms of CAP (primary care and hospital emergency departments) undertook to collaborate in the study. A case-by-case assessment was organized on a daily basis to identify all clinically suspected CAP patients living in the area. Predefined criteria for registration were based on acute lower respiratory tract infection, for which antibiotics were prescribed, associated with new focal signs on examination of the chest [11] and a radiographic infiltrate indicative of pneumonia, which was required for all suspected cases. This register involved all physicians working in public (covering $95.2 \%$ of the population) and private healthcare facilities in the study area (medical consulting rooms, primary healthcare centres and three regional hospitals), as well as reference hospitals outside the area (see Appendix). Periodic meetings and weekly phone contacts were held to improve the system of reporting cases. Patients with human immunodeficiency virus (HIV), active cancer, aspiration pneumonia or active lung tuberculosis, and patients from nursing homes or who had been discharged from hospital $<7$ days before the onset of symptoms were excluded from the study.

Of all clinically suspected CAP patients presenting from December 1, 1993 to November 30, 1995, 292 fulfilled the clinical and radiological entry criteria. For each patient, two serial blood samples were drawn for culture analysis at the time of initial diagnosis and mostly (87.3\%) before starting antibiotic treatment. When lower respiratory tract secretions or pleural fluid were available, these were also cultured. Sera were collected at the time of initial diagnosis and 4 weeks later. Paired sera were tested against evidence of antibodies to bacterial and viral agents; a four-fold or greater antibody titre rise was accepted as evidence of infection. Urine samples were collected to test for specific antigens.

All CAP cases were re-evaluated by chest radiography on the fifth day of illness and at monthly intervals until complete recovery. Cases of suspected pneumonia were discarded after finding another noninfectious respiratory disorder (51 cases), HIV (17 cases) or cancers (five cases). After inclusion, 14 patients could not be interviewed because six had died, five had dementia, and three could not be contacted. Finally, 205 CAP cases remained in the study.

For each case three control subjects were recruited. This was achieved within 21 days from the initial diagnosis of the respective case. Controls were randomly selected from the municipal census and matched by municipality, sex and age ( \pm 5 yrs). Most contacted controls who did not participate in the study were replaced following the same sampling and matching criteria. A total of 685 control subjects were contacted to participate in the study, of whom $13.3 \%$ declined to answer the questionnaire, $8.5 \%$ were not present for work or leisure reasons, $0.3 \%$ were not present for health reasons; $7.4 \%$ had other reasons and $1.2 \%$ had unknown reasons. Finally, 475 control subjects participated in the study.

\section{Data collection}

A questionnaire on CAP risk factors was composed from the current literature and the opinion of several experts (see Acknowledgements). It was administered directly to the cases and controls by trained young physicians and nurses at home, except for some inpatient cases who were interviewed at the end of their hospital stay. The questionnaire included standardized information on the patient's self-reported weight and height, life history of smoking, alcohol consumption during the fast year, life conditions during the last month (daily contact with children, animals at home, hours using motorbike or bicycle, sport and travelling), exposure to air conditioning and housing characteristics (kind of housing, density of people, number of exterior windows, asphalted or paved street, proximity of factories giving off smoke or dust, recent turning over of the soil within $100 \mathrm{~m}$, combustible cooker, kitchen ventilation and regular use of vacuum cleaner). It also included details on the patient's medical history and regular treatments during the last year.

In order to assess the reliability of the questionnaire, 36 interviews ( 14 cases and 22 controls) were repeated by the same interviewer within a period of 3 weeks. The results of the reliability study showed good agreement for most variables (82.9-100.0\%). The lowest weighted kappa indices of agreement were 0.54 for history of diabetes and 0.74 for chronic bronchitis.

\section{Analysis}

As a measure of association between risk factors and the occurrence of CAP, estimations of the relative risk through odds ratios (OR) were used. These were calculated using conditional logistic regression and presented with 95\% confidence intervals (CI) [12]. All variables were first univariately analysed and only those close to statistical significance (i.e. $\mathrm{p} \leq 0.05$ ) were used to fit a multivariate model. It was initially constructed with significant risk factors on the patients lifestyle and medical history; then it was expanded with those significant variables on medical treatments. Variables were added into the model taking into account improvement in the goodness of fit according to the deviance between the models. Ordered variables were analysed with the test for trend.

\section{Results}

Out of the total number of cases, $54.6 \%$ were males, with a mean \pm SD age of $56.1 \pm 19.0 \mathrm{yrs}$, and $45.4 \%$ females, with a mean age of $51.1 \pm 20.7 \mathrm{yrs} ; 47.3 \%$ of cases were treated at home and the remainder were admitted to hospital (15 patients to an intensive care unit). Microbiological diagnosis was positive in $42.9 \%$ of the cases; Streptococcus pneumoniae and Chlamydia pneumoniae were the most frequent agents (table 1).

Lifestyle risk factors possibly related to CAP from univariate logistic analysis are shown in table 2. Compared with normal weight, underweight subjects showed a marked increase in the risk of CAP $(\mathrm{OR}=2.04,95 \% \mathrm{CI}=1.08$ 3.88). Smoking was consistently related to the risk of CAP: compared with never-smokers, exsmokers had a higher risk of pneumonia $(\mathrm{OR}=2.16,95 \% \mathrm{CI}=1.26-3.69)$, and for those currently smoking $>20$ cigarettes day $^{-1}$ the risk increased to $3.89(95 \% \mathrm{CI}=1.75-8.64)$. Neither the frequency nor the intensity of alcohol intake showed a significant increase in risk. Daily contact with children overall or by different age groups did not relate to the 
Table 1. - Distribution of pathogens in cases with community-acquired pneumonia

\begin{tabular}{lrr}
\hline & $\mathrm{n}$ & $\%$ \\
\hline Streptococcus pneumoniae & 19 & 9.3 \\
Chlamydia pneumoniae & 19 & 9.3 \\
Mycoplasma pneumoniae & 7 & 3.4 \\
Coxiella burnetii & 4 & 2.0 \\
Respiratory syncitial virus (RSV) & 4 & 2.0 \\
Influenza B & 7 & 3.4 \\
Influenza A & 6 & 2.9 \\
Varicella & 1 & 0.5 \\
Haemophilus influenzae & 1 & 0.5 \\
Legionella pneumophila & 5 & 2.4 \\
Parainfluenza virus & 4 & 2.0 \\
Adenovirus & 2 & 1.0 \\
S. pneumoniae + C. pneumoniae & 1 & 0.5 \\
S. pneumoniae + influenza A & 3 & 1.5 \\
S. pneumoniae + M. pneumoniae & 1 & 0.5 \\
C. pneumoniae + adenovirus & 1 & 0.5 \\
Coxiella burnetii + influenza A & 1 & 0.5 \\
S. pneumoniae + RSV & 1 & 0.5 \\
S. pneumoniae + parainfluenza & 1 & 0.5 \\
Unknown & 117 & 57.1 \\
\hline Total number of cases & 205 & 100.0 \\
\hline
\end{tabular}

acquisition of CAP, neither did living with pets or farm animals. Other studied life conditions, including the use of motorbikes and bicycles, recent travel and hours per week of swimming or practising sport in open or closed facilities, were not associated with the risk of CAP (results not shown). Finally, none of the studied characteristics of the dwelling showed any difference between cases and controls.

The univariate analysis on the subject's medical history is shown in table 3 . The analysis of hospital admissions during the previous 5 yrs did not show any association with the risk of CAP. Permanent bedrest did not show a significant risk either. Medical interventions on the upper airway or adjacent areas during the previous year (i.e. rhinolaryngological examination, bronchoscopy or gastroscopy, nasogastric intubation and general anaesthesia) did not significantly increase the risk of CAP. Having had the tonsils or adenoids removed, a dental or periodontal infectious disease or a respiratory vaccination in the last year did not relate to the risk of pneumonia. Respiratory infections during the previous month (mainly cold, but also noninfectious rhinitis and acute tracheobronchitis) were strongly associated $(\mathrm{OR}=3.05,95 \% \mathrm{CI}=2.09-4.45)$. If these respiratory infections were repeated over the previous year they still remained significantly related to CAP $(\mathrm{OR}=1.52,95 \% \mathrm{CI}=1.03-2.24)$. Past history of CAP was strongly related with current cases $(\mathrm{OR}=2.11,95 \% \mathrm{CI}=$ 1.39-3.20), even if CAP had occurred $>5$ yrs before $(\mathrm{OR}=2.06,95 \% \mathrm{CI}=1.03-4.10)$; the risk increased if the past CAP was confirmed by radiography $(\mathrm{OR}=3.36,95 \%$ $\mathrm{CI}=2.01-5.61)$ and decreased according to the years from diagnosis ( $p<0.001$ for trend). From the list of underlying diseases presented in table 3 , the risk of CAP associated with chronic bronchitis, chronic liver disease, diagnosed asthma, history of lung tuberculosis and diabetes treated with oral hypoglycaemics or insulin stand out. The number of debilitating and immunosuppressive diseases was strongly related to the risk of CAP (p-value for trend $<0.001$ and 0.01 , respectively).

The results on medical treatments taken regularly during the previous year are shown in table 4 . Respiratory drugs such as aminophylline, aerosols and plastic pear-spacers (used to deliver inhalation therapy) were related to the occurrence of pneumonia. In contrast, benzodiazepines showed a strong protective effect $(\mathrm{OR}=0.55,95 \% \mathrm{CI}=$ 0.31-0.99).

The results of multivariate conditional logistic regression analyses of variables relating lifestyle, medical history and medical treatments are presented in table 5 . Cigarette smoking, respiratory infections in the previous month and chronic bronchitis were independent risk factors for CAP. Lung tuberculosis, aminophylline and, to a lesser degree, lower weight and past CAP confirmed by radiography maintained a high odds ratio $(\mathrm{OR}=2.37,95 \%$ $\mathrm{CI}=0.87-6.47 ; 2.68,0.70-10.26 ; 1.76,0.85-3.67$; and $1.75,0.96-3.20$, respectively), but did not reach significance. The univariate effect of diabetes, asthma, chronic liver disease and use of aerosols disappeared. Finally, the protective effect of benzodiazepines remained significant $(\mathrm{OR}=0.46,95 \% \mathrm{CI}=0.23-0.94)$.

\section{Discussion}

Despite the extensive availability of antibiotics, CAP remains an important cause of mortality and hospitalization. Most previous findings on risk factors associated with pneumonia have been derived from studies based on selected groups of patients. Several studies have been conducted with pneumonia acquired in hospitalized patients [13-18]. Other studies on CAP have been carried out on cases requiring hospitalization using patients hospitalized for other diseases as controls [19, 20], and patients admitted to intensive care units have been used to study risk factors for severe pneumonia [21-23]. Furthermore, many studies have been conducted on pneumonias caused by specific pathogens [24-31]. To the authors' knowledge, the only previous population-based study on true CAP was that of KoIVULA et al. [32], but this was a cross-sectional study on the elderly and no information on smoking was available.

One of the major advantages of the present case-control study is that it is population based. In addition, all CAP cases occurring in the entire population of a defined area within a 2-yr period were included. Thus, this study avoided the potential selection biases that affect the studies restricted to hospitalized patients and/or selected groups of pneumonia. In agreement with the hospitalization rate in Spain [6], 47.3\% of CAP patients were treated at home. The area is relatively small, but it enabled the identification and study of all suspected pneumonia cases registered by physicians through a prospective case-identification system. The estimated incidence of CAP, as a result of this study, was lower than the rates reported in other countries. Although the possibility of underreportiing of cases always exists, this incidence rate is similar to previous studies in the same and close areas $[6,33]$. Furthermore, a high participation rate of population controls was obtained. 
Table 2. - Univariate odds ratios (OR) for community-acquired pneumonia according to lifestyle and habits

\begin{tabular}{|c|c|c|c|c|c|}
\hline & $\begin{array}{l}\text { Controls } \\
(n=475)\end{array}$ & $\begin{array}{c}\text { Cases } \\
(\mathrm{n}=205)\end{array}$ & OR & $95 \% \mathrm{CI}$ & p-value \\
\hline \multicolumn{6}{|l|}{ Body mass index ${ }^{\dagger}$} \\
\hline Normal weight & 315 & 126 & 1.00 & & \\
\hline Underweight & 29 & 23 & 2.01 & $1.06-3.81$ & 0.033 \\
\hline Overweight & 98 & 34 & 0.83 & $0.52-1.32$ & 0.43 \\
\hline Highly overweight & 28 & 18 & 1.57 & $0.80-3.05$ & 0.19 \\
\hline \multicolumn{6}{|l|}{ Smoking status } \\
\hline Never-smoker & 208 & 72 & 1.00 & & \\
\hline Exsmoker & 131 & 67 & 2.16 & $1.26-3.69$ & 0.005 \\
\hline Smoker: $\quad 1-9$ cigarettes $\cdot$ day $^{-1}$ & 32 & 9 & 1.12 & $0.47-2.67$ & 0.80 \\
\hline $10-20$ cigarettes $\cdot$ day $^{-1}$ & 66 & 29 & 1.68 & $0.90-3.14$ & 0.10 \\
\hline$>20$ cigarettes $\cdot$ day $^{-1}$ & 21 & 21 & 3.89 & $1.75-8.64$ & $<0.001$ \\
\hline$\chi^{2}$ trend & & & & & 0.004 \\
\hline Life smoking (mean \pm SD) & $1.3 \pm 2.1$ & $1.8 \pm 2.5$ & $1.19^{*}$ & $1.07-1.33$ & 0.001 \\
\hline \multicolumn{6}{|c|}{ Frequency of alcohol intake during the last year } \\
\hline Never & 150 & 67 & 1.00 & & \\
\hline Occasional $^{*}$ & 104 & 37 & 0.82 & $0.49-1.36$ & 0.44 \\
\hline Usual & 221 & 101 & 1.11 & $0.72-1.72$ & 0.65 \\
\hline$\chi^{2}$ trend & & & & & 0.58 \\
\hline \multicolumn{6}{|l|}{ Quartiles of alcohol intake $g \cdot$ day $^{-1}$} \\
\hline 0 & 254 & 104 & 1.00 & & \\
\hline $1-5.07$ & 55 & 18 & 0.83 & $0.45-1.54$ & 0.56 \\
\hline $5.08-14.11$ & 50 & 26 & 1.35 & $0.77-2.35$ & 0.29 \\
\hline $14.12-35.51$ & 60 & 33 & 1.53 & $0.89-2.61$ & 0.12 \\
\hline$>35.51$ & 56 & 24 & 1.22 & $0.65-2.31$ & 0.54 \\
\hline$\chi^{2}$ trend & & & & & 0.18 \\
\hline Contact with children, last month & 238 & 117 & 1.28 & $0.91-1.80$ & 0.16 \\
\hline Contact with pets & 242 & 113 & 1.21 & $0.86-1.72$ & 0.28 \\
\hline
\end{tabular}

${ }^{\dagger}$ : Cut-off points are defined by 20.7, 27.8 and 31.1 in males, and 19.1, 27.3 and 32.3 in females. $*$ : for each 10 -pack $\cdot \mathrm{yr}^{-1}$; ${ }^{\star}$ : less than one intake per week of any alcoholic drink. CI: confidence interval.

An increase in the risk of CAP was found to be associated with smoking status, the number of cigarettes smoked per day and lifetime smoking. A trend towards increased risk was observed for increase in duration, average intensity and cumulative exposure. Smoking is a well-known and important risk factor for CAP, through alterations in mechanisms of the host defence system [34]. There is consistent evidence to show increased respiratory infections in smokers compared with nonsmokers [35] and studies on selected groups of pneumonia have observed an association with smoking habits [13, 24-26, 28-31, 36].

No association between CAP and alcohol intake was observed in this study. In a Finnish population-based study [32] a high risk of CAP associated with alcoholism was found, but alcoholism was rarely reported (only $0.4 \%$ of the population). In one hospital-based case-control study, high alcohol intake was found to be the only independent risk factor for CAP [20], but in another study it was not associated [19]. The pattern of alcohol consumption by groups of age and sex in the present control subjects was compared with that observed in another survey on lifestyle habits, based on a representative sample of the general population in the same area [37]. The pattern of alcohol consumption was very similar. According to the results, the association between high alcohol intake and CAP observed in other studies might be due to selection or information bias.

A very high risk of CAP associated with upper repeated respiratory infections in the previous month was observed. Previous infection by respiratory viruses has long been regarded as a factor that predisposes to pneumonia [38] and the occurrence of pneumococcal disease has been associated with the isolation of respiratory viruses [39].

People with a previous diagnosis of pneumonia, confirmed by radiological findings, had a nearly two-fold higher risk of a subsequent CAP. The risk was progressively higher for recent episodes than for older ones. It has previously been observed $[40,41]$ that readmission for pneumonia within 3 yrs after discharge is higher in patients with an initial diagnosis of pneumonia than with other infectious diseases.

Several underlying chronic diseases were associated with an increased risk for contracting CAP in the univariate analysis, but in a multivariate analysis, adjusting for several confounding and risk factors, $\mathrm{CB}$ was the only one that remained statistically significant. Negative results in disorders with a relatively small prevalence of exposure may reflect a low statistical power. In addition, questionnaire data on self-reported diseases with unestablished diagnostic criteria or a fluctuating course can result in unreliable information [42]; this may cause a nondifferential underreporting of some chronic diseases and produce a tendency towards the null hypothesis in statistical testing. CB has been observed as a risk factor in other studies on CAP [31, 32] and nosocomial pneumonia [18]. In contrast, a history of diabetes (which was overreported by the present controls and had a relatively low index of agreement in the repeatibility study) and heart disease were not associated with CAP, as observed in other studies [31, 32]. Malnutrition status has been associated with the risk 
Table 3. - Univariate odds ratios (OR) for community-acquired pneumonia according to medical history

\begin{tabular}{lccccc}
\hline & $\begin{array}{c}\text { Controls } \\
(\mathrm{n}=475)\end{array}$ & $\begin{array}{c}\text { Cases } \\
(\mathrm{n}=205)\end{array}$ & OR & $95 \%$ CI & p-value \\
\hline Hospital admissions, last 5 yrs & 192 & 87 & 1.13 & $0.80-1.60$ & 0.49 \\
Bedridden for 3 months & 20 & 9 & 0.81 & $0.34-1.89$ & 0.62 \\
Upper airway explorations, last yr & 48 & 17 & 0.81 & $0.45-1.46$ & 0.48 \\
Tonsillectomy/adenoidectomy & 105 & 42 & 0.92 & $0.59-1.44$ & 0.72 \\
Visit to the dentist, last month & 54 & 18 & 0.66 & $0.37-1.20$ & 0.17 \\
Dental or periodontal infectious disease & 381 & 166 & 1.17 & $0.74-1.83$ & 0.51 \\
Influenza vaccination, last yr & 147 & 63 & 1.03 & $0.66-1.60$ & 0.90 \\
Any respiratory vaccination, last yr & 148 & 68 & 1.19 & $0.77-1.83$ & 0.45 \\
Respiratory infection, last month & & & & \\
Cold & 88 & 82 & 3.58 & $2.28-5.64$ & $<0.001$ \\
Any respiratory infection & 137 & 109 & 3.05 & $2.09-4.45$ & $<0.001$ \\
Contact with people with respiratory infection & 181 & 77 & 0.95 & $0.66-1.37$ & 0.79 \\
Previous pneumonia confirmed by radiograph & 33 & 43 & 3.36 & $2.01-5.61$ & $<0.001$ \\
Underlying diseases & & & & \\
Treated diabetes & 27 & 19 & 1.86 & $0.98-3.52$ & 0.061 \\
Cardiopathy & 36 & 14 & 0.88 & $0.45-1.72$ & 0.72 \\
Chronic bronchitis & 73 & 63 & 3.20 & $1.98-5.15$ & $<0.001$ \\
Diagnosed asthma & 16 & 14 & 2.12 & $1.01-4.47$ & 0.052 \\
Lung tuberculosis & 18 & 13 & 2.01 & $0.93-4.36$ & 0.083 \\
Neurological disease & 26 & 16 & 1.42 & $0.74-2.75$ & 0.30 \\
Gastric disease/symptoms & 156 & 71 & 1.05 & $0.71-1.53$ & 0.82 \\
Chronic liver disease & 12 & 11 & 2.60 & $1.04-6.51$ & 0.043 \\
Renal failure & 4 & 1 & 0.63 & $0.07-5.68$ & 0.67 \\
Depression/anxiety & 76 & 32 & 0.98 & $0.60-1.60$ & 0.93 \\
Cancer & 13 & 10 & 2.03 & $0.82-5.04$ & 0.13 \\
\hline CI confir & & & & & \\
\hline
\end{tabular}

CI: confidence interval.

of CAP [19] or with the risk of death from pneumonia [41]. Subjects in the present study with a low body mass index had an increased risk of CAP.

In animal studies it was observed that aminophylline suppresses pulmonary antibacterial defences by impairing the recruitment and bactericidal capacities of polymorphonuclear leukocytes responding to bacterial challenge [43]. In the present study, after adjusting for other factors such as $\mathrm{CB}$ and asthma, the effect of aerosol disappeared and the effect of aminophylline and plastic pear-spacers ceased to be statistically significant. Further research is needed to confirm these findings. Neither was a protective effect of influenza vaccination observed, as suggested by other studies [44]. An important protective effect associated with the intake of benzodiazepines during the previous year was found. This effect has not been observed previously, but it could be explained by the fact that benzodiazepines would decrease rather than increase oesophagic microaspirations by reducing muscle relaxation in rapid eye movement sleep [45]. Finally, regarding corticosteroids, which are marked immunodepressive drugs [46], no increase in risk associated with oral intake was found, but exposure was observed in only 11 cases and 12 controls.

This study provides new and more established evidence on the factors associated with the occurrence of pneumonia in the adult community. While it gives support to some identified risk factors, it contributes to the emergence of new ones. Larger studies are needed to assess the effect of some risk factors with low prevalence in the general population. The knowledge of the true risk factors will provide the opportunity to identify those groups of persons at risk and assign closely directed preventive interventions or special medical care services.

\begin{abstract}
Acknowledgements. The authors thank J.T. Grayston (University of Washington, USA), M.J. Fine (University of Pittsburgh, USA), C. Jokinen (Kuopio University Hospital, Finland), F. Manresa (Hospital de Belivitge, Spain) and J. Roig (Hospital Ntra. Sra. de Maritxell, Andorra) for their advice in the design of the questionnaire on CAP risk factors, J. Garau (Hospital Mutua de Terrassa, Spain), J.T. Macfarlane (Nottingham City Hospital, UK), J. Morera (Hospital Germans Trias y Pujol, Spain) and A. Torres (Hospital Clínic i Provincial de Barcelona, Spain) for their advice in the discussion of the results. The authors are grateful to $\mathrm{C}$. Mas for administrative tasks.
\end{abstract}

\section{Appendix}

The participants in the Maresme CAP study were as follows.

\section{Primary care centres}

J. Costa, M. Tristany, E. Carrillo, M.J. Castany, C. Costa, J. Grau, G. Lozano, (Health Basic Area of Arenys, Institut Català de la Salut, ICS), P. Subias, B. Jimeno, V. Marina, M. Casanovas, A. Gardella, M.C. Ginés, A. Bragnovich, M. Fradera (Health Basic Area of Canet de Mar and Sant Pol de Mar, ICS), P. Flores, P. Serra, E. Torrellas, J.L. Fernandez, J. Mussoll (Health Basic Area of Cirera Molins, Serveis de Prevenció Assistencials i SòcioSanitaris, PASS), A. Armada, X. Mestres, Y. Ortega, M. Roger, C. Guardiola, M.T. Gros, N. Les (Health Basic Area 
Table 4. - Univariate odds ratios (OR) for community-acquired pneumonia according to regular treatments used during the last year

\begin{tabular}{|c|c|c|c|c|c|}
\hline & $\begin{array}{l}\text { Control } \\
(\mathrm{n}=475)\end{array}$ & $\begin{array}{l}\text { ases } \\
=205 \text { ) }\end{array}$ & OR & $95 \% \mathrm{CI}$ & p-value \\
\hline$N$-acetyl cysteine & 11 & 6 & 1.48 & $0.53-4.14$ & 0.47 \\
\hline Acetylsalicilic acid & 52 & 24 & 1.15 & $0.66-2.01$ & 0.63 \\
\hline Oral corticosteroids & 12 & 11 & 2.09 & $0.91-4.81$ & 0.08 \\
\hline $\begin{array}{l}\text { Inhaled } \\
\text { corticosteroids }\end{array}$ & 31 & 21 & 1.62 & $0.88-2.99$ & 0.12 \\
\hline Digoxin & 19 & 10 & 1.16 & $0.51-2.65$ & 0.72 \\
\hline Amiodarone & 3 & 3 & 3.00 & $0.61-14.86$ & 0.19 \\
\hline Diuretics & 55 & 21 & 0.86 & $0.45-1.62$ & 0.63 \\
\hline Aminophylline & 12 & 12 & 2.53 & $1.03-6.18$ & 0.042 \\
\hline Calcium antagonist & 48 & 20 & 1.08 & $0.61-1.91$ & 0.79 \\
\hline Benzodiazepines & 69 & 20 & 0.55 & $0.31-0.99$ & 0.041 \\
\hline $\begin{array}{l}\text { Drugs against } \\
\text { ulcers }\end{array}$ & 69 & 31 & 0.99 & $0.61-1.60$ & 0.95 \\
\hline $\begin{array}{l}\text { Oral } \\
\text { hypoglycaemics }\end{array}$ & 13 & 10 & 1.92 & $0.80-4.64$ & 0.15 \\
\hline Nasal drops & 7 & 3 & 0.73 & $0.18-2.92$ & 0.65 \\
\hline Oxygen & 4 & 2 & 1.07 & $0.19-6.02$ & 0.94 \\
\hline Aerosols & 26 & 20 & 1.86 & $0.98-3.51$ & 0.059 \\
\hline Plastic pear-spacers & 19 & 22 & 2.94 & $1.52-5.71$ & 0.001 \\
\hline
\end{tabular}

CI: confidence interval.

of Ronda Cerdanya, ICS), M. Aizpurua, J. Domenech, J. Massons, M. Bundó, M.C. Trilla, P. Toran, J. Joanola (Health Basic Area of Ronda Prim, ICS), M. Biscarri (Health Basic Area of Caldes d'Estrach, ICS), G. Aresté, M.A. Sanchez (Health Basic Area of Cabrera de Mar, ICS), G. Calvo, O. Martí, M. Catalá, J.V. Sorribas, M. Alegre (Health Basic Area of Argentona, ICS), J.M. Cuyubamba (Health Basic Area of Dosrius, ICS), A. Borrás, F. Aznar (Centre Mèdic de Mataró).

Table 5. - Multivariate odds ratios (OR) of communityacquired pneumonia for factors relating to lifestyle, medical history and medical treatments during the last year

\begin{tabular}{|c|c|c|c|}
\hline & OR & $95 \% \mathrm{CI}$ & p-value \\
\hline Low weight & 1.76 & $0.85-3.67$ & 0.13 \\
\hline Overweight & 0.91 & $0.52-1.59$ & 0.74 \\
\hline Highly overweight & 1.42 & $0.63-3.24$ & 0.40 \\
\hline Exsmoker & 1.58 & $0.86-2.91$ & 0.14 \\
\hline Smoker: $1-9$ cigarettes $\cdot$ day $^{-1}$ & 0.80 & $0.32-2.05$ & 0.65 \\
\hline $10-20$ cigarettes $\cdot$ day $^{-1}$ & 1.40 & $0.69-2.81$ & 0.35 \\
\hline$>20$ cigarettes $^{\prime}$ day $^{-1}$ & 2.77 & $1.14-6.70$ & 0.024 \\
\hline $\begin{array}{l}\text { Any respiratory infection, } \\
\text { last month }\end{array}$ & 2.73 & $1.75-4.26$ & $<0.001$ \\
\hline $\begin{array}{l}\text { Previous pneumonia confirmed } \\
\text { by radiograph }\end{array}$ & 1.75 & 0.96 & 0.069 \\
\hline Treated diabetes & 1.61 & 0.69 & 0.27 \\
\hline Chro & 2.22 & 1.1 & 0.021 \\
\hline Diag & 1.14 & 0.40 & 0.81 \\
\hline Lung tuberculos & 2.37 & $0.87-6.47$ & 0.092 \\
\hline Chronic liver disease & 1.18 & $0.36-3.83$ & 0.79 \\
\hline Benzodiazepines & 0.46 & $0.23-0.94$ & 0.032 \\
\hline Aminophyline & 2.68 & $0.70-10.26$ & 0.15 \\
\hline & 0.77 & $0.31-1.91$ & 0.58 \\
\hline Plastic pear-spacers & 1.26 & $0.46-3.46$ & 0.65 \\
\hline
\end{tabular}

CI: confidence interval.

\section{Hospital centres}

F. Riera (Hospital de Barcelona, Barcelona), O. Parra (Hospital del Sagrat Cor, Barcelona), P. Tudela, A. Carreras (Hospital Germans Trias y Pujol, Badalona), J. Calzada (Hospital Sant Jaume, Calella), J.M. Gil, J. Bassa, M. Pujol, M. Daza, F. Riera, F. Casarramona, and R. Priu (Hospitals del Consorci Sanitari de Mataró, Mataró).

\section{Microbiology laboratories}

G. Sauca (Hospitals del Consorci Sanitari de Mataró, Mataró), P. Coll (Hospital de St Pau, Barcelona) and J. Vidal (Hospital Clínic, Barcelona).

\section{Fieldwork team}

L. Congost, T. Lladó, J. Dalmau, M. Jorba, C. Pascual, I. Tarruella, I. Picazo, E. Esquerra, and M. Ferrer.

\section{References}

1. The National Health Survey. Current estimates from the National Health Interview Survey. United States 1981. The National Health Survey, series 10, no. 141. Washington, DC, US Government Printing Office, 1982.

2. Pneumonia and influenza death rates: United States, 1979-1994. MMWR 1995; 44: 535-537.

3. Garibaldi RA. Epidemiology of community acquired respiratory tract infections in adults: incidence, etiology and impact. Am J Med 1985; 78: 32-37.

4. Macfarlane JT. Community-acquired pneumonia. $\mathrm{Br} J$ Dis Chest 1987; 81: 116-127.

5. Jokinen C, Heiskanen L, Juvonen $\mathrm{H}$, et al. Incidence of community-acquired pneumonia in the population of four municipalities in eastern Finland. Am J Epidemiol 1993; 137: 977-988.

6. Almirall J, Morato I, Riera F, et al. Incidence of community-acquired pneumonia and Chlamydia pneumoniae infection: a prospective multicentre study. Eur Respir $J$ 1993; 6: 14-18.

7. Macfarlane JT, Colville A, Guion A, MacFarlane RM, Rosed H. Prospective study of aetiology and outcome of adult lower respiratory tract infections in the community. Lancet 1993; 341: 511-514.

8. Esposito AL. Community-acquired pneumococcal pneumonia: effect of age on manifestations and outcome. Arch Intern Med 1984; 144: 945-948.

9. Reynolds HY. Host defense impairments that may lead to respiratory infections. Clin Chest Med 1987; 8: 339358.

10. Ginesu F, Pirina P. Etiology and risk factors of adult pneumonia. J Chemother 1995; 7: 277-285.

11. Woodhead MA, Macfarlane JT, McCracken JS, Rose DH, Finch RG. Prospective study of the aetiology and outcome of pneumonia in the community. Lancet 1987; ii: 671-674.

12. Breslow NE, Day NE. Statistical methods in cancer research. Vol. 1, The analysis of case-control studies (IARC Scientific publications No. 32). Lyon, International Agency for Research on Cancer, 1980.

13. Stopinski J, Staib Y, Weissbach M. Do nicotine and alcohol abuse effect the occurrence of postoperative 
bacterial infections? Langenbecks Arch Chir 1993; 378: 125-128.

14. Konrad F, Wiedeck H, Kilian J, Deller A. Risk factors in nosocomial pneumonia in intensive care patients: a prospective study to identify high-risk patients. Anaesthesist 1991; 40: 483-490.

15. Cunnion KM, Weber DJ, Broadhead WE, Hanson LC, Pieper CF, Rutala WA. Risk factors for nosocomial pneumonia: comparing adult critical-care populations. $A m J$ Respir Crit Care Med 1996; 153: 158-162.

16. Barreiro B, Dorca J, Esteban L, et al. Risk factors for the development of Haemophilus influenzae pneumonia in hospitalized adults. Eur Respir $J$ 1995; 8: 1543-1547.

17. Tryba M, Cook DJ. Gastric alkalinization, pneumonia, and systemic infections: the controversy. Scand J Gastroenterol 1995; 210: Suppl. 5, 53-59.

18. Celis R, Torres A, Gatell JM, Almela M, RodríguezRoisin R, Agustí-Vidal A. Nosocomial pneumonia: a multivariate analysis of risk and prognosis. Chest 1988; 93: 318-324.

19. Riquelme R, Torres A, El-Ebiary M, et al. Communityacquired pneumonia in the elderly: a multivariate analysis of risk and prognostic factors. Am J Respir Crit Care Med 1996; 154: 1450-1455.

20. Fernandez-Sola J, Junque A, Estruch R, Monforte R, Torres A, Urbano-Marquez A. High alcohol intake as a risk and prognostic factor for community-acquired pneumonia. Arch Intern Med 1995; 155: 1649-1654.

21. Torres A, Serra-Batlles J, Ferrer A, et al. Severe community-acquired pneumonia: epidemiology and prognostic factors. Am Rev Respir Dis 1991; 144: 312-318.

22. Feldman C, Ross S, Mahomed AG, Omar J, Smith C. The aetiology of severe community-acquired pneumonia and its impact on initial, empiric, antimicrobial chemotherapy. Respir Med 1995; 89: 187-192.

23. Moine P, Vercken JB, Chevret S, Gajdos P. Severe community-acquired pneumococcal pneumonia: the French study group of community-acquired pneumonia in ICU. Scand J Infect Dis 1995; 27: 201-206.

24. Straus WL, Plouffe JF, File TM Jr, et al. Risk factors for domestic acquisition of Legionnaires disease. Ohio Legionnaires disease group. Arch Intern Med 1996; 156: 1685-1692.

25. Pedro-Botet ML, Sabria-Leal M, Haro M, Gimenez G, Sopena N, Tor J. Nosocomial and community-acquired Legionella pneumonia: clinical comparative analysis. Eur Respir J 1995; 8: 1929-1933.

26. Falco V, Fernandez de Sevilla T, Alegre J, Ferrer A, Martinez Vazquez JM. Legionella pneumophila: a cause of severe community-acquired pneumonia. Chest 1991; 100: 1007-1011.

27. Carratalá J, Gudiol F, Pallares R, et al. Risk factors for nosocomial Legionella pneumophila pneumonia. Am J Respir Crit Care Med 1994; 149: 625-629.

28. Watanabe Y, Kanayama H, Kato K, et al. Liver disorders in patients with Mycoplasma pneumoniae pneumonia. Nippon Kyobu Shikkan Gakk Zasshi 1991; 29: 693-697.

29. Nauffal D, Menendez R, Morales P, et al. Community viral pneumonia in the adult population: a prospective multicenter study of 62 cases: the pneumonia study group of the community of Valencia. Rev Clin Esp 1990; 187 : 229-232.

30. Karvonen M, Tuomilehto J, Pitkäniemi J, Naukkarinen A, Saikku P. Importance of smoking for Chlamydia pneumoniae seropositivity. Int J Epidemiol 1994; 23: 13151321.

31. Lipsky BA, Boyko EJ, Inui TS, Koepsell TD. Risk factors for acquiring pneumococcal infections. Arch Intern Med 1986; 146: 2179-2218.

32. Koivula I, Sten M, Mäkelä PH. Risk factors for pneumonia in the elderly. Am J Med 1994; 96: 313-320.

33. Santos de Unamuno C, Llorente San Martń MA, Carandell Jäger $\mathrm{E}$, et al. Lugar de atención, etiologá y tratamiento de las neumonás adquiridas en la comunidad de Palma de Mallorca. Med Clin (Barc) 1998; 110: 290294.

34. Marcy TW, Merril WW. Cigarette smoking and respiratory tract infection. Clin Chest Med 1987; 8: 381-391.

35. Sherman CB. The health consequences of cigarette smoking: pulmonary diseases. Med Clin North Am 1992; 76: 355-375.

36. Lange P, Vestbo J, Nyboe J. Risk factors for death and hospitalization from pneumonia: a prospective study of a general population. Eur Respir J 1995; 8: 1694-1698.

37. Bolibar I, Pera G. Enquesta de Salut de Mataro 1994. Mataro (Barcelona), Institut de Recerca Epidemiològica i Clinica, 1996.

38. Rose RM, Pinkston P, O'Donnell C, Jensen WA. Viral infection in the lower respiratory tract. Clin Chest Med 1987; 8: 405-418.

39. Kim PE, Musher DM, Glezen WP, Rodriguez-Barradas MC, Nahm WK, Wright ChE. Association of invasive pneumococcal disease with season, atmospheric conditions, air pollution, and the isolation of respiratory viruses. Clin Infect Dis 1996; 22: 100-106.

40. Hedlund JU, Ortqvist AB, Kalin M, Scalia-Tomba G, Giesecke J. Risk of pneumonia in patients previously treated in hospital for pneumonia. Lancet 1992; 340: 396397.

41. Hedlund J. Community-acquired pneumonia requiring hospitalisation: factors of importance for the short-and long term prognosis. Scand J Infect Dis 1995; 97: 11-60.

42. Haapanen N, Miilunpalo S, Pasanen M, Oja P, Vuori I. Agreement between questionnaire data and medical records of chronic disease in middle-aged elderly Finnish men and women. Am J Epidemiol 1997; 145: 762-769.

43. Nelson S, Summer WR, Jakab W. Aminophylline-induced suppression of pulmonary antibacterial defenses. $\mathrm{Am}$ Rev Respir Dis 1985; 131: 923-927.

44. Gross PA, Hermogenes AW, Sacks HS, Lau J, Levandowski RA. The efficacy of influenza vaccine in elderly persons: a meta analysis and review of the literature. Ann Intern Med 1995; 123: 518-527.

45. Gaillard JM. Benzodiazepines and GABA-ergic transmission. In: Kryger MH, Roth $\mathrm{T}$, Dement WC, eds. Principles and Practice of Sleep Medicine. Philadelphia, PA, WB Saunders, 1989; pp. 213-218.

46. Skerrett SJ, Niederman MS, Fein AM. Respiratory infections and acute lung injury in systemic illness. Clin Chest Med 1989; 10: 469-502. 